\title{
Industrial treatment processes for the recycling of green foundry sands
}

\author{
S. Fiore \& M. C. Zanetti \\ DITAG, Politecnico di Torino, Italy
}

\begin{abstract}
Three treatment processes for the reclamation of green moulding sands coming out from a cast iron foundry located in Northern Italy are considered in this study. A wet mechanical treatment, a dry mechanical treatment and a dry mechanical plus thermal treatment are compared to evaluate the efficiency of each process and to point out the best regeneration solution for the recycling of reclaimed sand in foundry operations. The inflow and the outflow samples of each process were characterized by means of particle-size analysis and the determination of silica, loss on ignition, acid request, oolitic and some metals contents.

A final evaluation of the three processes was performed taking into account the obtained quality of recovered silica sand and the economical aspects; the wet mechanical and the dry mechanical plus thermal treatments are the most effective for the recovery of green moulding sands coming out from Teksid foundry plant for cold-box core production.

Keywords: bentonite bonded moulding sand, green sand, foundry waste recycling.
\end{abstract}

\section{Introduction}

Exhaust sands represent a crucial issue in the management of foundry wastes: a ferrous foundry of secondary fusion produces an amount of wastes varying from $25 \%$ to $100 \%$ b.w. respect to the final product, and the $30-60 \%$ of these wastes is made of core and moulding sands (EPA [1]). Therefore the optimization of processes aimed to the recycling of exhaust foundry sands is particularly interesting. 
The Teksid cast iron foundry plant located in Crescentino (Vercelli, Northern Italy) and considered in this study actually produces about $700-800 \mathrm{t} / \mathrm{d}$ of casts for the automotive industry and about 750-800 t/d of wastes. The production process is made of the following phases: furnace charge preparation, mould and core manufacture, pattern making, melting and casting, shakeout, cleaning and finishing operations (steel shotting, painting and thermal treatment). Green sand moulding and hot/cold box processes are performed in Teksid plant respectively for mould and core manufacture.

Green sand moulding, accounting for about $85 \%$ of ferrous casts produced in the world (EPA [2]), employs a mixture of silica sand (80-95\% b.w.), clay (3$10 \%$ b.w.), coal dust (2-10\% b.w.) and water (3-4\% b.w.) (Schleg [3]). The word "green" denotes the absence of any drying or baking phase (Luther [4]). Water activates the binding action of the clay on silica sand, and the coal dust burns off at contact with the molten metal, preventing its oxidation and increasing the refractory properties of the mould.

Cores are made of silica sand and organic binders, and should be harder and stronger than moulds, because they are required to resist the pressure of the molten metal that fills the mould (EPA [5]). The considered foundry plant employs two methods for core production: the hot-box process, in which silica sand is mixed with $1 \%$ b.w. phenolic resin and $0.8 \%$ b.w. of ammonium nitrate and urea as catalysts, and then heated at $230-260^{\circ} \mathrm{C}$ until solidification; and the cold-box process, in which silica sand is mixed with $1.3 \%$ b.w. phenolic resin, $0.9 \%$ b.w. isocyanic resin and $0.1 \%$ b.w. trimethylamine gas as catalyst, and no heating is required.

The wastes produced in Teksid foundry consist mainly of moulding sands and dusts from dust abatement plants on moulding lines $(464 \mathrm{t} / \mathrm{d})$, muds from dust abatement plants on moulding lines and furnaces $(150 \mathrm{t} / \mathrm{d})$, furnace and ladle slags $(100 \mathrm{t} / \mathrm{d})$, broken cores $(50 \mathrm{t} / \mathrm{d})$, powders and muds from dust abatement plant on furnaces and finishing operations $(8 \mathrm{t} / \mathrm{d})$, exhaust lime $(6 \mathrm{t} / \mathrm{d})$. The authors evaluated in another study (Zanetti et al. [6]) the reuse/recycle possibilities for all the mentioned residues.

Spent sands account for about the $60 \%$ of the total wastes generated by the considered plant and make a relevant amount of residues; the aim of this study is to evaluate a proper solution for their reclamation, taking into account both economic and environmental aspects.

The reclamation of moulding sands for the recycling in mould and core production is essentially based on the following aspects (EPA [2], Schleg [3]): right particle-size range (Teksid plant requirements consider a range between 0.1 and $0.4 \mathrm{~mm}$ ), and elimination of bentonite, coal dust and metallic plus nonmetallic impurities. The dimensional range and the coal dust and impurities elimination may be easily achieved by means of a sieving operation (metal fins and mould and core fragments cumulate preferentially in large fractions, while coal dust is particularly present in fine fractions). Instead bentonite is located as free particles in fine fractions, but also forms a hard shell (defined "oolitic") that surrounds the silica sand grains, which may be broken by means of mechanical treatments. 


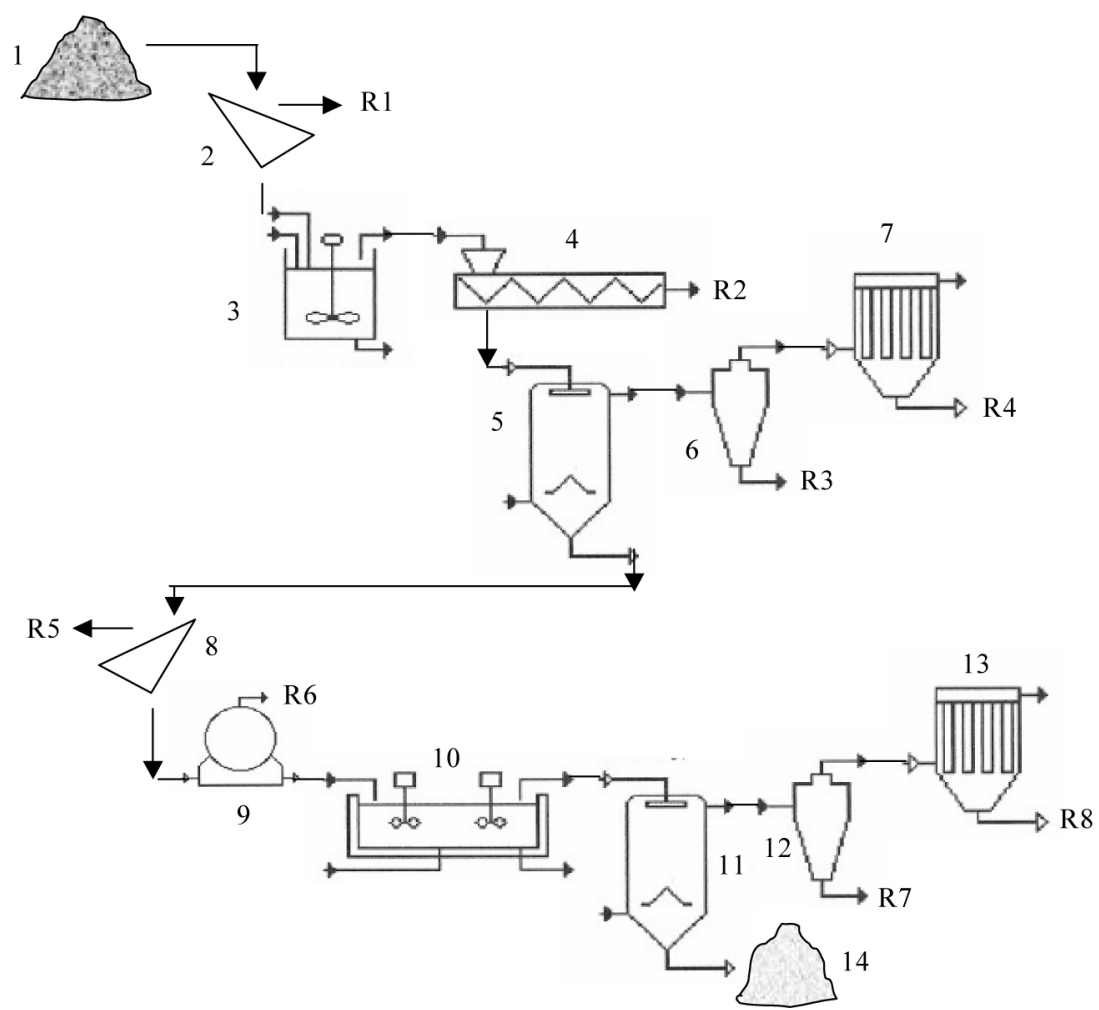

Legend: 1.feed, 2.screen $100 \mathrm{~mm}, \mathrm{R} 1$. residues $\mathrm{d}>100 \mathrm{~mm}, 3$. attrition cell, 4 . screw conveyor, R2. fine particles $(\mathrm{d}<0.1 \mathrm{~mm}), 5,11$. drier, 6,12. cyclone, R3, R7. cyclone coarse fraction, 7,13. bag filter, R4,R8. bag filter particles, 8. screen 0.7 $\mathrm{mm}, \mathrm{R} 5$. residues $\mathrm{d}>0.7 \mathrm{~mm}, 9$. rotating barrel magnetic separator, R6. magnetic fraction, 10. sulphuric acid lixiviation, 14. final product.

Figure 1: $\quad$ Scheme of the wet mechanical reclamation treatment.

\section{Treatment processes}

Three reclamation processes, all performed on industrial scale on the spent moulding sands coming out from the Teksid plant, are compared in this study: a wet mechanical treatment, a dry mechanical treatment and a dry mechanical plus thermal treatment. The obtained clean sands from the three mentioned processes were chemically characterized.

\subsection{Wet mechanical treatment}

A wet mechanical treatment was tested on $500 \mathrm{t}$ of green moulding sand coming out from the considered Teksid foundry in a plant, situated in Northern Italy, that 
usually performs the treatment of residues from granite mining for glass and ceramic production. The treatment cycle adopted is schematised in Figure 1.

The reclamation treatment produces $80 \%$ b.w. of clean sand, $15 \%$ b.w. of fine particles from the screw conveyor and $5 \%$ b.w. of magnetic products and fine particles from cyclone and bag filter. The authors proposed in another work (Zanetti and Fiore [9]) the recycle of the fine particles from the screw conveyor in mould manufacture and their reuse in the ceramic industry for tile production.

\subsection{Dry mechanical treatment}

A dry mechanical treatment was tested on $500 \mathrm{t}$ of green moulding sand coming out from the considered Teksid foundry in a pilot plant that foresees a dry attrition phase. The reclamation treatment is based on a dry mechanical process: the dried sand grains are fed between metal blade drums that rotate at $1 \mathrm{rpm}$ and a stone grinding wheel, which rotates at $40 \mathrm{rpm}$, thus obtaining the break of the oolitic shell and the rounding off of the silica particles. A scheme of the plant is shown in Figure 2.

The dry mechanical reclamation treatment produces about the $80 \%$ b.w. of clean sand.

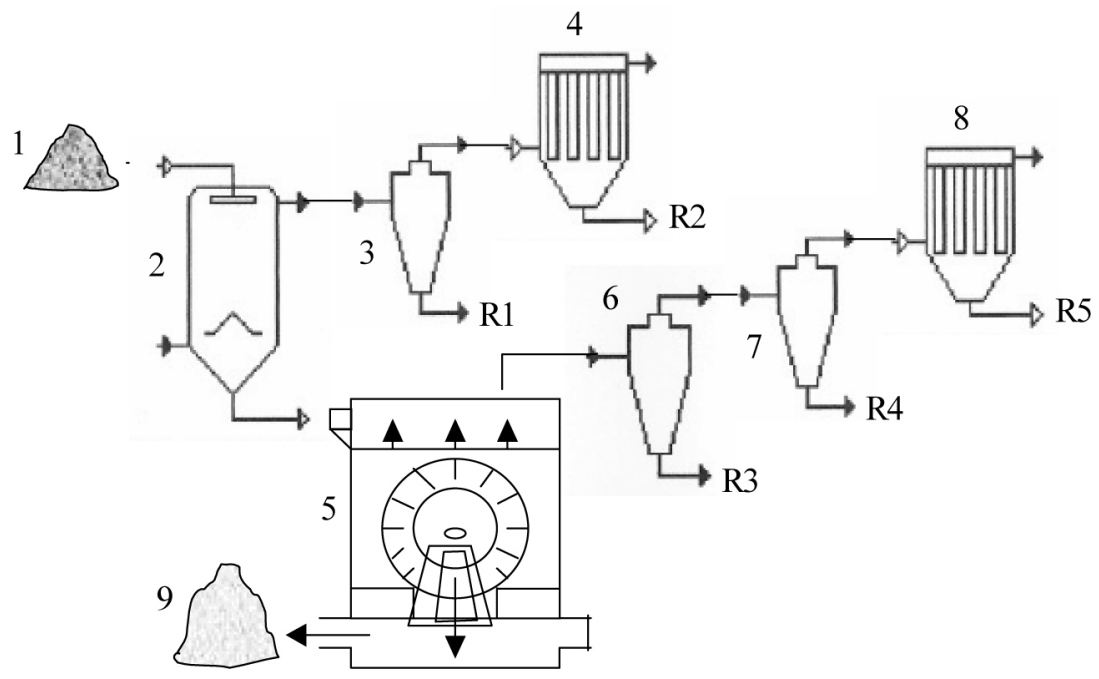

Legend: 1. feed, 2. drier, 3,6,7. cyclone, R1,R3,R4. cyclone coarse fraction, 4,8. bag filter, R2,R5. bag filter particles, 5. sand cleaner, 9. final product

Figure 2: $\quad$ Scheme of the dry mechanical reclamation treatment.

\subsection{Dry mechanical plus thermal treatment}

A dry mechanical plus thermal process is applied in a treatment plant situated in the considered Teksid foundry. The regeneration treatment is schematised in 
Figure 3. After a sieving and a magnetic separation, a low intensity pneumatic mechanical scrubbing treatment is performed, then a thermal treatment at a temperature of $800 \div 900{ }^{\circ} \mathrm{C}$, finally a high intensity pneumatic mechanical scrubbing treatment. The plant is designed to perform the reclamation of $600 \mathrm{t} / \mathrm{d}$ of green moulding sand for mould and core manufacture, with a theoretical efficiency of the $80 \%$.

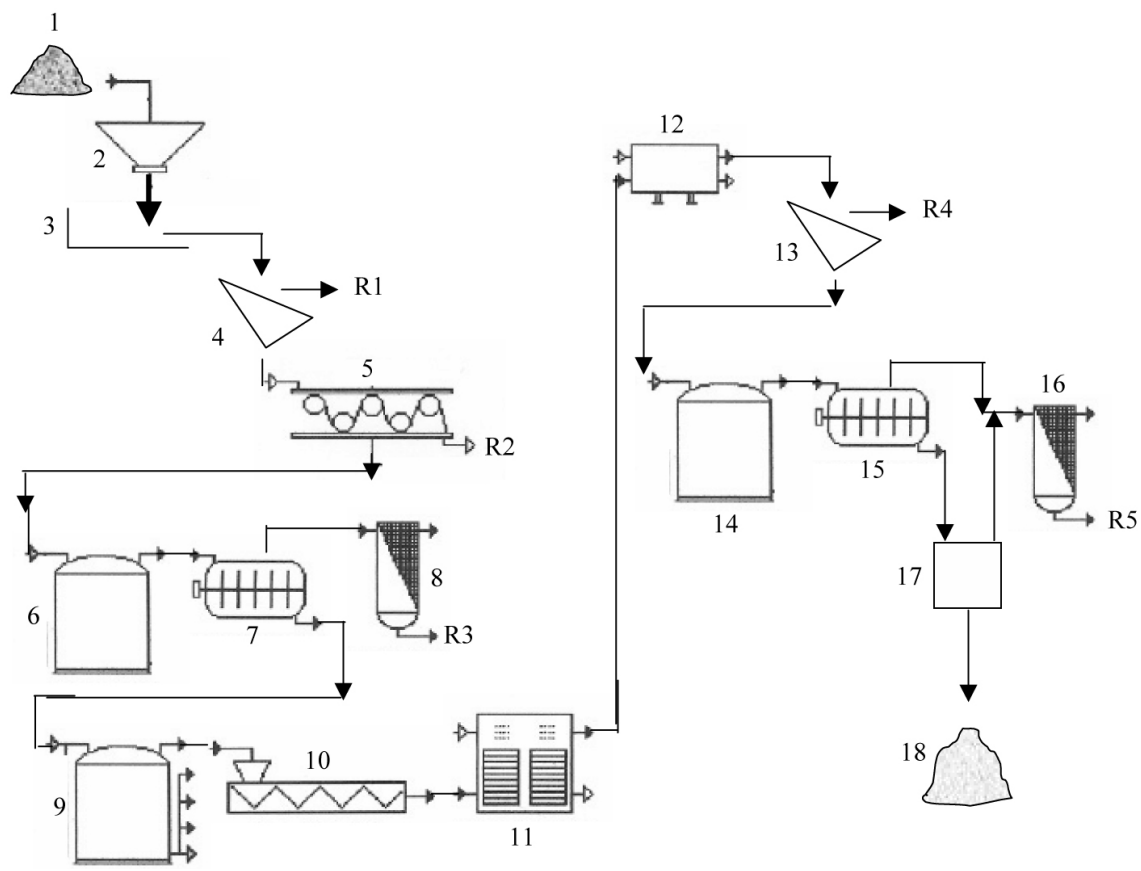

Legend: 1. feed, 2. shaking feeder, 3. shaking extractor, 4. screen, R1. iron residues $(\mathrm{d}>0.6 \mathrm{~mm}), 5$. magnetic belt separator, $\mathrm{R} 2$. magnetic fraction, 6 . storage, 7. scrubber (high intensity), 8 and 16. dedusting (cyclone and bag filter), R3. not inert fine particles, 9. storage, 10.screw conveyor, 11. Hot Rec furnaces, 12. cooling, 13. sieve, R4. residues $(\mathrm{d}>0.4 \mathrm{~mm})$, 14. storage, 15. scrubber (low density), R5. inert fine particles, 17 . dedusting, 18. final product

Figure 3: $\quad$ Scheme of the dry mechanical plus thermal reclamation treatment.

The produced residues are mainly of two kinds: not inert fine particles $(15 \%$ of the feed) and inert fine particles (5\% of the feed). The word "inert" refers to a minimum content of active clay that may be referred to the thermal resistance of the bentonite employed in green sand moulding. The authors proposed in another study (Zanetti et al. [6]) the reuse of not inert fine particles in mould manufacture, and the recycling of inert fine particles as raw material for the concrete industry. 


\section{Materials and methods}

All the reagents employed are A.C.S. grade and the flasks and the glassware are A class. All the analyses were performed on dried samples, performing reference procedures (UNI [7]).

The particle-size analysis was realized on samples of about $5 \mathrm{~kg}$ reduced to a mass of about $400 \mathrm{~g}$ by means of a Jones splitter, using a Ro-Tap Tyler mechanical siever equipped with six Tyler mesh sieves $\left(2^{1 / 4}\right.$ ratio) for 10 minutes. All the weighing operations were performed by means of a balance ( $0.01 \mathrm{~g}$ sensitivity). The inflow samples were at first wet sieved at a $0.025 \mathrm{~mm}$ and $0.038 \mathrm{~mm}$ dimension before the particle size analysis. The particle-size analysis below the $0.025 \mathrm{~mm}$ dimension was performed by means of the Andreasen apparatus.

The AFS grain fineness number shows the number of silica grains kept per 1 $\mathrm{mm}^{2}$ of the sieve surface: a high value of this parameter means the existence of a high number of fine particles. This index is calculated after the particle-size distribution analysis, each elementary percentage being multiplied for a fixed number (Sundeen [8]). The sum of these values divided for the total weigh of the sample determines the grain fineness number.

The Acid Demand Value (at $\mathrm{pH}$ 5) is determined by means of the addition of $50 \mathrm{ml}$ of distilled water and $50 \mathrm{ml}$ of $0.1 \mathrm{~N}$ hydrochloric acid to a sample of a weight equal to $50 \mathrm{~g}$. After 15 minutes of vigorous stirring, the sample is washed twice with $100 \mathrm{ml}$ of distilled water, and the liquid phases are titrated, using a Orion $420 \mathrm{pH}$-meter, with a $0.1 \mathrm{~N}$ sodium hydroxide solution till a $\mathrm{pH}$ value equal to 5 is reached.

The oolitic content determination requires the addition of $200 \mathrm{ml}$ of $6 \mathrm{~N}$ hydrochloric acid to a sample of a weight equal to $50 \mathrm{~g}$ that has previously been heated to a temperature of $900^{\circ} \mathrm{C}$ for 4 hours. The mixture is then boiled for 25 minutes. The sand is washed with distilled water until no more acidity is detected and then $250 \mathrm{ml}$ of distilled water and $60 \mathrm{~g}$ of potassium hydroxide are added. The mixture is boiled for a further 25 minutes, the sand is washed again with distilled water until no more alkalinity is detected, and the residue is filtrated and dried. The difference ( $\%$ b.w.) between the input sample and the treated one gives the oolitic content.

The Loss on Ignition (L.O.I.) was evaluated by roasting $2 \mathrm{~g}$ of dried sample at the temperature of $900^{\circ} \mathrm{C}$ for 3 hours. The weight difference (\% b.w.) between the starting sample and the roasted one gives the searched value.

The metals (Na, K, Ca, Mg, Fe, Cr, Zn) contents were obtained through an acid digestion of $0.5 \mathrm{~g}$ sand with $6 \mathrm{ml}$ of $32 \%$ hydrochloric acid and $2 \mathrm{ml}$ of $65 \%$ nitric acid in a microwave oven. The digested samples were filtrated on a Whatman grade 44 filters and on the obtained solutions the metals contents determination was performed by means of an FAAS. For the silica determination the filtered solid residue underwent to a calcination phase $\left(900{ }^{\circ} \mathrm{C}\right.$ for 30 minutes) and a new acid digestion in the microwave oven with $6 \mathrm{ml}$ of $40 \%$ fluoridric acid. The obtained solution is filtrated and the solid residue was calcinated at $900{ }^{\circ} \mathrm{C}$ for 30 minutes. 
The Aluminium content was gathered through an acid digestion of $0.25 \mathrm{~g}$ sand with $2 \mathrm{ml}$ of $96 \%$ sulphuric acid and $2.5 \mathrm{ml}$ of $85 \%$ phosphoric acid in a microwave oven. $5 \mathrm{ml}$ of fluoridric acid were added to the digested samples and a new digestion phase was performed. The digested samples were filtrated on a Whatman grade 44 filters and on the obtained solutions the Aluminium content determination was performed by means of FAAS.

\section{Results and discussion}

The efficiency of each one of the above-described treatments is evaluated to single out the different regeneration solutions for the recycling of the reclaimed sand in mould and core manufacture. The yields of the three reclamation treatments are comparable, as the amount of produced residues, for which the authors proposed some recycle/reuse possibilities in other studies (Zanetti et al. [6], Zanetti and Fiore [9]). The reclaimed sand obtained by means of the wet mechanical treatment has been tested by the authors, with positive results, for cold-box core manufacture and for glass production (Zanetti et al. [10]).

The inflow and the outflow samples of each process were characterized by means of a particle-size analysis and the determination of silica, loss on ignition, acid request, oolitic and some metals contents. The results of the performed analyses are compared in Table 1 with Teksid foundry requirements for reclaimed sand employed in cold-box core production.

Considering dimensional parameters, the dry mechanical treatment process produces a higher amount of fine particles, compared to the wet mechanical process. The fine particles amount produced by the dry mechanical plus thermal treatment is comparable with the value given by the dry mechanical process. The amounts b.w. of the particles having dimensions above $0.4 \mathrm{~mm}$ in the outflows are similar.

The Acid Demand Value (at $\mathrm{pH}$ 5) is the total acid quantity that the basic compounds contained in the recovered sand succeed in neutralizing. Alkaline substances (such as carbonates but also $\mathrm{Na}, \mathrm{K}, \mathrm{Ca}, \mathrm{Mg}$ oxides) react with acidic catalysts added to the resin in core manufacture, thus reducing the efficiency of the resin-catalyst reaction; alkaline substances also reduce the refractoriness of the sand. The inflow Acid Demand Value is particularly high because of the significant content of fine particles, rich of bentonite (containing relevant amounts of alkaline substances and oxides). Wet mechanical and dry mechanical plus thermal treatments comply with foundry limits, otherwise the dry mechanical process produces a high residual Acid Demand Value, probably due to a not efficient bentonite removal. This is confirmed by the sodium and iron contents found in the outflow of the dry mechanical treatment, although the residual iron content is also caused by the absence of any magnetic separation phase.

The Loss on Ignition (L.O.I.) value, determined by organic substances (mainly coal dust and resins) and carbonates, represents a measure of the volume of gaseous products that will form at the contact of the molten metal with the mould and the core. Too high L.O.I. values are undesirable, because they may 
imply defects on casts surface. While all regeneration treatments respect foundry requirements, the dry mechanical plus thermal process is particularly effective in the abatement of the L.O.I. value, because of the high temperature achieved.

Table 1: Characterization of the inflow and the outflows of the considered reclamation treatments evaluated for the regeneration of green moulding sands of Teksid foundry plant.

\begin{tabular}{|c|c|c|c|c|c|}
\hline \multirow[b]{2}{*}{ Parameter } & \multirow[b]{2}{*}{ Inflow } & \multicolumn{3}{|c|}{ Outflows } & \multirow[b]{2}{*}{$\begin{array}{c}\text { Teksid } \\
\text { Foundry } \\
\text { requirements }\end{array}$} \\
\hline & & $\begin{array}{c}\text { Wet } \\
\text { mechanical } \\
\text { treatment }\end{array}$ & $\begin{array}{c}\text { Dry } \\
\text { mechanical } \\
\text { treatment }\end{array}$ & $\begin{array}{c}\text { Dry } \\
\text { mechanical } \\
+ \text { thermal } \\
\text { treatment }\end{array}$ & \\
\hline $\begin{array}{c}\mathrm{d}<0.1 \mathrm{~mm} \\
(\% \text { b.w. })\end{array}$ & 10 & 0.11 & 0.20 & $0.50^{*}$ & 0.30 \\
\hline AFS & $50.38 *$ & 48.21 & 52.16 & $48.56^{*}$ & $44 \div 52$ \\
\hline $\begin{array}{c}\mathrm{d}>0.4 \mathrm{~mm} \\
(\% \text { b.w. })\end{array}$ & 20 & 10 & 8.7 & l & l \\
\hline $\begin{array}{l}\text { Acid Demand } \\
\text { Value (ml) }\end{array}$ & $48.0 *$ & 1.5 & 10.7 & $2.9^{*}$ & $0-6$ \\
\hline $\begin{array}{l}\text { Loss on Ignition } \\
\text { (\% b.w.) }\end{array}$ & $3.02 *$ & 0.45 & 0.64 & $0.04 *$ & 2.00 \\
\hline Oolitic (\% b.w.) & 6.6 & 1.7 & 3.9 & 1 & 2.0 \\
\hline$\% \mathrm{Na}$ & 0.17 & 0.02 & 0.12 & 1 & 1 \\
\hline$\% \mathrm{~K}$ & 0.04 & 1 & 0.02 & 1 & 1 \\
\hline$\% \mathrm{Ca}$ & 0.03 & $<0.01$ & $<0.01$ & 1 & 1 \\
\hline$\% \mathrm{Mg}$ & 0.32 & 1 & 0.03 & 1 & 1 \\
\hline$\% \mathrm{Fe}$ & 0.77 & 0.04 & 0.25 & 1 & 1 \\
\hline$\% \mathrm{Cr}$ & $<0.005$ & $<0.005$ & 0.010 & 1 & 1 \\
\hline$\% \mathrm{Zn}$ & 0.004 & 1 & 0.002 & 1 & 1 \\
\hline$\% \mathrm{Al}$ & 0.53 & $<0.005$ & 0.13 & 1 & 1 \\
\hline$\%$ total oxides & 2.88 & 0.13 & 0.87 & 1 & 1.00 \\
\hline
\end{tabular}

*data obtained from an external laboratory.

The oolitic content indicates the ageing degree of the sand, because the clay used as binding agent after the melt creates a shell around the silica grains. This clay layer should not be very thick, or the casts may present some surface defects. The dry mechanical process doesn't comply with foundry limits, on the contrary the wet mechanical treatment, characterised by multiple attrition phases (initial attrition with water, then the action of the screw conveyor, finally the lixiviation with sulphuric acid) is particularly efficient in breaking the oolitic shell.

Total oxides must be kept below $1 \%$ b.w. to assure the refractoriness required in foundry operations. Both wet mechanical and dry mechanical processes comply with foundry requirements about total oxides contents; the higher value given by the dry mechanical treatment, mainly due to iron content, is caused by the absence of any magnetic separation phase. 
Silica content of the reclaimed products has to be high, not less of the $90 \%$ b.w., to ensure the thermal resistance of moulds and cores; some tests performed by the authors showed that in all the three cases there aren't any problems in reaching that value, and that the best result was gathered by means of the wet mechanical treatment.

\section{Conclusions}

The results of the performed analyses show that the wet mechanical treatment and the dry mechanical plus thermal treatment are the most effective for the recovery of green moulding sands coming out from Teksid foundry plant for cold-box core production. In fact the oolitic content and acid demand values are better than the ones obtained from the dry mechanical treatment. However the wet mechanical treatment involves a noticeable sludge production and a treatment cost about equal to $0.02-0.03 € / \mathrm{kg}$. The involved cost of the dry mechanical plus thermal process is about equal to $0.03-0.04 € / \mathrm{kg}$. The dry mechanical process is economical $(0.01 € / \mathrm{kg})$, but because of the high gathered acid demand value (about $10 \mathrm{ml}$ ) requires a change in the cold-box core making foundry operations for the compliance of the recovered foundry sand.

\section{References}

[1] EPA United States Environmental Protection Agency, Summary of factors affecting compliance by ferrous foundries, vol.1, EPA-340/1-80-020, Washington, pp.34-49, 1981.

[2] EPA United States Environmental Protection Agency, Profile of the Metal Casting Industry, EPA/310/R-97/004, pp.15-22, 77-84, 1997.

[3] Schleg, F., Guide to casting and molding processes, Engineered Casting Solutions 2(3), pp.18-27, 2000.

[4] Luther, N.B., Metalcasting and molding processes, Casting Source Directory 7(1), pp.29-35, 1997.

[5] EPA United States Environmental Protection Agency, Guides to Pollution Prevention, Metal Casting and Heat Treating Industry, EPA/625/R92/009, pp.5-12, 1992.

[6] Zanetti, M.C., Fiore, S., Clerici, C., Recycling and reutilization of cast foundry wastes, Proc. of XXII International Mineral Processing Congress, eds. L. Lorenzen, D.J. Bradshaw, Document Transformation Technologies: Cape Town, ISBN: 0-958-46092-2, pp.1836-1844, 2003.

[7] UNI, Italian National Standards Body, Foundry sand. Sampling and test methods, UNI 4628:1976.

[8] Sundeen, S.P., Geological study of sand deposits in the State of Michigan, Phase II, final report - 1978, Open file report-OFR 78 04, Institute of Mineral Research Michigan Technological University, pp. 6-7. http://www.deq.state.mi.us/documents/deq-gsd-sanddune-OFR7804.pdf 
76 Waste Management and the Environment III

[9] Zanetti, M.C., Fiore, S., Foundry waste recycling in moulding operations and in the ceramic industry, Waste Management \& Research 21, pp. 235 242, 2003.

[10] Zanetti, M.C., Fiore, S., Clerici, C., Reuse of foundry sands for core and glass production, Journal of Solid Waste Technology and Management 30(1), pp. 28-36, 2004. 